BANGLADESH J CHILD HEALTH 2009; VOL 33 (3): 83-89

\title{
Risk Factors and Short-Term Outcome of Birth Asphyxiated Babies in Dhaka Medical College Hospital
}

\author{
NILUFAR SHIREEN ${ }^{1}$, NAZMUN NAHAR ${ }^{2}$, AH MOLLAH $^{3}$
}

\begin{abstract}
Background: Perinatal asphyxia is the most important preventable cause of cerebral injury in the neonatal period leading to very high neonatal mortality and morbidity in developing countries. Little can be done for a baby affected by severe perinatal asphyxia. So, prevention is unquestionably desired.

Objective: To identify the maternal and fetal risk factors for the development of birth asphyxiated babies and to see the short term outcome of the affected babies.

Methods: An analytical type of or observational study was done in the Special Care Baby Unit (SCBU) of Dhaka Medical College Hospital from October 2003 to March 2004. Identification of the risk factors was done by retrospective comparison of the cases and controls. Outcome was analyzed by cross sectional comparative study. One hundred consecutive cases of birth asphyxia, admitted in SCBU, were enrolled in the study. Another 30 neonates admitted during this period for other reasons (i.e., jaundice, septicemia, low birth weight) were taken as control. Necessary information were collected by detailed history taking, clinical examination and close follow up of the hospital course, using pre-designed questionnaire and recording form.

Results: Male: female ratio 3:2 both in the cases and controls. Mean age on admission was 13.8 hours and 2.6 days for case and control respectively. Identified important maternal risk factors were primiparity (57\% in cases vs. 33.3\% in control), hypertension (16.6\% vs. 3.3\%), pre-eclamptic toxemia of pregnancy (24\% vs. $13.3 \%)$, prolonged rupture of membrane (33.3\% vs. 6.7\%), prolonged labour (34\% vs. 3.3\%) and use of oxytocin during labour ( $16 \%$ vs. none). All these were statistically significant $(p<0.05)$. Serious neonatal complications noted among the asphyxiated babies were convulsion, hypoxic ishchemic encephalopathy and necrotizing enterocolitis. These were not seen among the control group. Mortality among the asphyxiated babies was $16 \%$ during hospital stay, whereas no fatality was recorded among the control. Neurological sequelae was observed in $28 \%$ of asphyxiated babies but was absent in controls.

Conclusion: All the identified risk factors as well as neonatal complications were significantly higher in asphyxiated babies. Most of these could have been prevented even with our limited resources.
\end{abstract}

Key words: Birth Asphyxia, risk factors, immediate outcome.

\section{Introduction}

Birth asphyxia is the most important cause of preventable cerebral injury occurring in the neonatal period. Full recovery may not occur and many children

1. MD Paediatric Hematology and Oncology (Final Part Student), Bangabandhu Sheikh Mujib Medical University, Dhaka

2. Professor and Head, Department of Paediatrics, BIRDEM Hospital and Ibrahim Medical College, Dhaka

3. Professor, Department of Neonatology, Dhaka Medical College and Hospital, Dhaka

Correspondence: Dr. Nilufar Shireen are left with life long neurological impairment and in some cases, incapacitating disability ${ }^{1}$. This creates a great burden for the family, as well as for the society. According to World Health Organization estimates, in the developing countries $3 \%$ of all infants (3.6 millions) suffer from moderate to severe birth asphyxia, of which $23 \%(840,000)$ die and approximately the same number develop serious sequelae ${ }^{2}$. Prevention is more important than treatment. In a poor country like Bangladesh, the need for risk assessment of birth asphyxia is thus obvious ${ }^{3}$. 
During the last 3 decades, under-five mortality and infant mortality rate (IMR) have decreased significantly in Bangladesh, but neonatal mortality remains very high. Out of 3.8 million babies born every year in Bangladesh, 1,50,000 babies die in the first 28 days of life, which is equivalent to one newborn in every 3.4 minutes. This is an unacceptably high neonatal mortality (36/1000 live birth) ${ }^{2}$.

There are very few epidemiological data on birth asphyxia (BA) in Bangladesh. Studies primarily based on hospital data, indicate that birth asphyxia is one of the three leading cause of newborn death. The other two being infection (sepsis, pneumonia, diarrhoea and tetanus), and complications of prematurity ${ }^{4-6}$. Majority of these death occurred within first 24 hours of life. Annual reports of Dhaka Medical College Hospital from 2001 through 2007 showed incidence of birth asphyxia to be from $29 \%$ to $36 \%$ and mortality among them were around $25 \% \%^{7,8}$. Another study showed incidence of birth asphyxia to be 9.76 per 1000 live birth $^{9}$. Considering these facts, the present study was carried out to identify the maternal and fetal risk factors for the occurrence of birth asphyxia and also to see their short term outcome of the affected babies.

\section{Materials and Methods}

The study was done from October 2003 to March 2004 in the Special Care Baby Unit (SCBU) of Dhaka Medical College Hospital (DMCH). It was a analytical type of observational study. Identification of the risk factors was done by retrospective comparison of the cases and controls. Outcome was analyzed by cross sectional comparative study.

One hundred consecutive cases of birth asphyxiated babies who were admitted during this period were taken as study cases. Another 30 patients who were admitted in $\mathrm{DMCH}$ SCBU during the study period for reasons other than perinatal asphyxia, were taken as control. They were matched for birth weight and gestational age. Birth asphyxia was considered when there was a history of failure or delayed onset of spontaneous respiration after birth or when a baby needed positive pressure ventilation for more than 1 minute. Those with congenital anomalies, Rh incompatibility or birth weight less than 1000 gm were excluded from the study.

The purpose of the study and the intended mode of handling the baby were explained to the working group, which included the peadiatricians, trainee doctors, intern doctors and also nurses. Enrollment was done within 12 hours of admission, after informed verbal consent from the mother or the attendant of each case. Detailed history was taken which included maternal age, working status, social status, past medical and obstetric history, parity, history of present pregnancy including hypertension, fever, antepartum haemorrhage (APH), jaundice, convulsion; whether antenatal checkup was taken or not. Place and mode of delivery, conducting person, cause of LUCS or instrumental delivery, duration of labour, prolonged rupture of membrane (PROM), use of any drug, colour of liquor, babies condition at birth, need for any form of resuscitation, with specification. Babies were examined regarding their weight, length, occipitofrontal circumference (OFC), temperature, heart rate, respiratory rate, colour, fontanelles, systemic examination of cardiovascular, respiratory, abdomen and particularly nervous system in terms of muscle tone and primitive reflexes. Any evidence of birth injury or anomaly was also noted. Gestational age in completed weeks was assessed by an accurate menstrual history and each case was confirmed by New Ballard scoring and in case of discrepancy, the later was taken.

Babies were followed up twice daily. Note was kept for pallor, cyanosis, apnoea, respiratory distress, level of consciousness, convulsion, muscle tone, abdominal distension, or GI bleeding.

Management was given according to the protocol of the unit. This was, calculated amount of intravenous fluid for first 48 hours, injectable antibiotics (Ampicillin and gentamycin, to start as empirical starting therapy), phenobarbitone for first 48 hours, and if necessary continued thereafter, gradual starting of enteral feeding and management of apnoea with bolus and infusion aminophylline and when needed, intubation and positive pressure ventilation. Other complications were addressed appropriately. Investigations, i.e, $\mathrm{Hb} \%$, total and differential counts of WBC, total platelet count, blood sugar, serum electrolyte were done when necessary.

Data analysis was done by SPSS (for windows, v11) and Microsoft Excel, uni-variate and bi-variate tables were prepared. Chi- square test was applied and $p$ values were calculated for the risk factors and outcome of babies.

\section{Results}

Male : female ratio was 3:2 in both cases and controls. Mean age at admission was 13.4 hours for asphyxiated 
babies and 2.6 days for the control group. Most of the neonates (60\%, 73.3\%) were inborn in both case and control groups. Percentage of $\mathrm{C} /$ section deliveries was also higher in both the groups. Most of the asphyxiated babies were full term (57\%), whereas, most of the control babies were preterm (60\%). No post term baby was seen among the control group, in contrast to $6 \%$ in asphyxia group (Table-I). Mean birth weight of the asphyxiated babies was $2407 \mathrm{gm}$ with a range of 1000$4100 \mathrm{gm}$ and in the control group, mean weight was $2031.7 \mathrm{gm}$ and range was $1100-3500 \mathrm{gm}$. About half (49\%) of the asphyxiated baby had normal birth weight (2500-3999 gm) in comparison of 30\% had normal birth weight in control group (Fig.-1).
Stratified age distribution of mothers of cases and control were almost similar. Also similar was the distribution of their various educational levels. More of the asphyxiated babies were born to primi mothers (57\%), than control group babies (33.3\%) (Table-I).

Among the identified risk factors hypertension, toxaemia of pregnancy, APH, oxytocin use during labour, prolonged 2nd stage of labour, multiple pregnancy and PROM, were found significantly higher in the asphyxiated group $(p<0.05)$ (Table-II). Observed neonatal complications were hypoxic ischemic encephalopathy (HIE) 45\% (mortality 12\%), convulsion $31 \%$ (mortality 4\%), jaundice $20 \%$ (mortality $1 \%$ ),

Table-I

Baseline Data of the study patients

\begin{tabular}{|c|c|c|}
\hline & $\begin{array}{c}\text { Case }(n=100) \\
n(\%)\end{array}$ & $\begin{array}{c}\text { Control }(\mathrm{n}=30) \\
\mathrm{n}(\%)\end{array}$ \\
\hline \multicolumn{3}{|l|}{ Babies } \\
\hline \multicolumn{3}{|l|}{ Place of delivery } \\
\hline Inborn (DMCH) & $60(60.0)$ & $22(73.3)$ \\
\hline Out born & $40(40.0)$ & $08(26.7)$ \\
\hline \multicolumn{3}{|l|}{ Mode of delivery } \\
\hline NVD & $49(49.0)$ & $11(36.7)$ \\
\hline LUCS & $51(51.0)$ & $19(63.3)$ \\
\hline \multicolumn{3}{|l|}{ Gestational age of baby ${ }^{\star \star \#}$} \\
\hline Preterm (<37 completed week) & $37(37.0)$ & $18(60.0)$ \\
\hline Term (37- 42 week) & $57(57.0)$ & $12(40.0)$ \\
\hline Post term (>42 week) & $06(6.0)$ & 0 \\
\hline \multicolumn{3}{|l|}{ Mothers } \\
\hline \multicolumn{3}{|l|}{ Age (years) } \\
\hline $15-19$ & $12(12.0)$ & 4 (13.3) \\
\hline $20-24$ & $42(42.0)$ & $9(30.0)$ \\
\hline $25-29$ & $33(33.0)$ & $10(33.3)$ \\
\hline $30-34$ & $04(4.0)$ & $4(13.3)$ \\
\hline$\geq 35$ & $09(9.0)$ & $3(10.0)$ \\
\hline \multicolumn{3}{|l|}{ Level of education } \\
\hline Illiterate & $39(39.0)$ & $15(50.0)$ \\
\hline Upto class 5 & $39(39.0)$ & 7 (23.3) \\
\hline Class 6 and above & $22(22.0)$ & $8(26.7)$ \\
\hline \multicolumn{3}{|l|}{ Parity*\# } \\
\hline Primi & $57(57.0)$ & $10(33.3)$ \\
\hline Multi & $43(43.0)$ & $20(66.7)$ \\
\hline \multicolumn{3}{|l|}{ Antenatal checkup } \\
\hline Regular (5 visit) & $22(22.0)$ & $9(30.0)$ \\
\hline Irregular or Nil & $78(78.0)$ & $21(70.0)$ \\
\hline
\end{tabular}

** $\chi^{2}$ test; ${ }^{*} \mathrm{P}$ value $<0.05$ 
septicemia 16\% (mortality 2\%), repeated apnoea $16 \%$ (mortality $8 \%$ ), respiratory distress 10\% (mortality 4\%), necrotizing enterocolitis $7 \%$ (mortality $5 \%$ ), feeding intolerance $6 \%$ (mortality $1 \%$ ) and cardiac arrest 3\% (mortality 1\%) (Fig.-2).

Among the control group, $20 \%(n=6)$ were clinically diagnosed as septicemia, 30\% ( $n=9)$ neonatal jaundice, and rest $50 \%(n=15)$ was low birth weight babies. Out of 6 septicemic baby $10 \%(n=3)$ developed jaundice later on and one of them required exchange transfusion. Only complication noted among the control group during their hospital stay was respiratory distress and feeding intolerance, 3.3\% $(n=1)$ each.

Average hospital stay was almost similar in both group. Twenty eight percent of the asphyxiated babies developed neurological sequelae and mortality was $16 \%$. No neurological sequelae or mortality was seen in control group (Table-III). In asphyxiated group 6\% neonates were posterm and mortality was highest $(66.6 \%)$ in this gestational age group (Table-IV). It is also seen that HIE in post term group was fatal (Fig.-3).

Table-II

The Antepartum and intrapartum risk factors, as was present among cases and controls

\begin{tabular}{|c|c|c|c|}
\hline Diseases/Factors & $\begin{array}{c}\text { Cases }(n=100) \\
n(\%)\end{array}$ & $\begin{array}{c}\text { Control }(n=30) \\
n(\%)\end{array}$ & P value* \\
\hline Hypertension & $16(16.0)$ & $01(3.3)$ & $0.003^{\star *}$ \\
\hline Toxaemia of pregnancy & $24(24.0)$ & $04(13.3)$ & $0.003^{\star \star}$ \\
\hline Antepartum haemorrhage (APH) & $09(9.0)$ & 0 & $0.001^{\star *}$ \\
\hline Prolonged ruptured membrne (PROM) & $33(33.0)$ & $02(6.7)$ & $0.002^{\star \star}$ \\
\hline Fever & $09(9.0)$ & $04(13.3)$ & 0.479 \\
\hline Prolonged $2^{\text {nd }}$ stage of labour & $34(34.0)$ & $01(3.3)$ & $<0.001^{\star *}$ \\
\hline Multiple pregnancy & $03(3.0)$ & $04(13.3)$ & $0.018^{* *}$ \\
\hline Malpresentation & $14(14.0)$ & $06(20.0)$ & 0.346 \\
\hline Oxytocin use during labour & $16(16.0)$ & 0 & $<0.001^{\star *}$ \\
\hline
\end{tabular}

Table-III

Number and percentage of cases and control by outcome

\begin{tabular}{lcc}
\hline Outcome & $\begin{array}{c}\text { Cases } \\
(\mathrm{n}=100)\end{array}$ & $\begin{array}{c}\text { Control } \\
(\mathrm{n}=30)\end{array}$ \\
\hline Average hospital stay & 4.84 days & 4.7 days \\
& $(12$ hours -16 days $)$ & $21(70 \%)$ \\
Discharged without apparent sequelae & $40(40 \%)$ & 0 \\
Discharged with neurological sequelae & $28(28 \%)$ & $09(30 \%)$ \\
Discharged on risk bond (DORB) & $16(16 \%)$ & 0 \\
Death & $16(16 \%)$ & \\
\hline
\end{tabular}


Table-IV

Mortality of cases in accordance with their gestational age

\begin{tabular}{lcc}
\hline Group & $\begin{array}{c}\text { Number of } \\
\text { cases } \\
\mathrm{N}(\%)\end{array}$ & $\begin{array}{c}\text { Mortality in } \\
\text { each group } \\
\mathrm{N}(\%)\end{array}$ \\
\hline Preterm & $37(37.0)$ & $6(16.2)$ \\
Full term & $57(57.0)$ & $6(10.5)$ \\
Post term & $6(6.0)$ & $4(66.6)$ \\
\hline
\end{tabular}

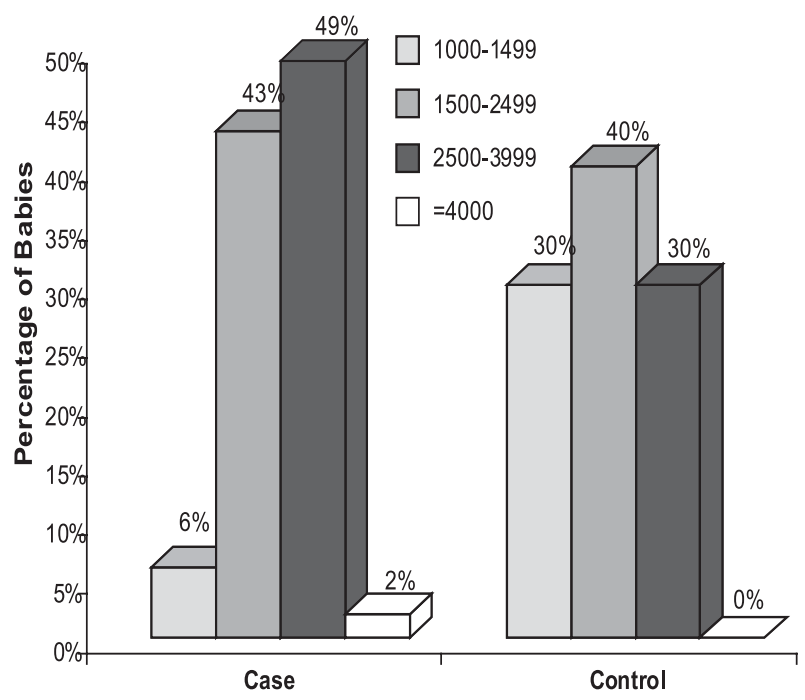

Fig.-1: Distribution of birth weight among cases and controls

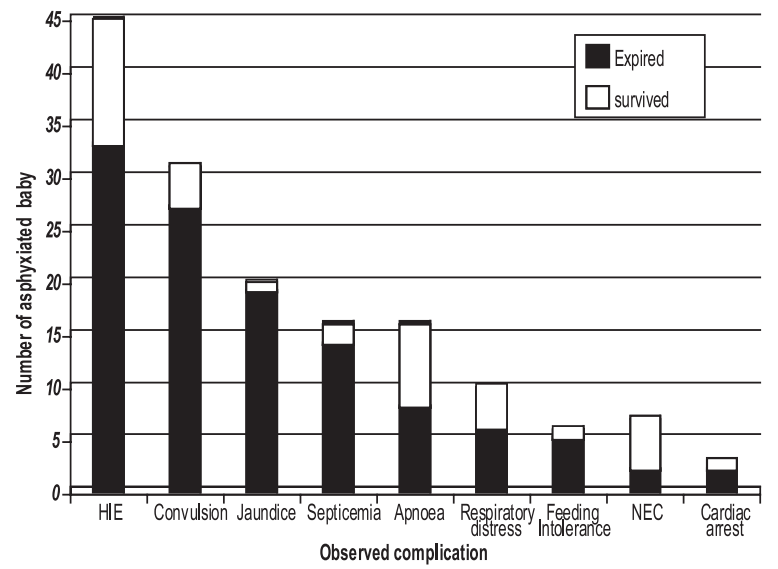

Fig.-2: Complications seen among the asphyxiated babies and fatality for each

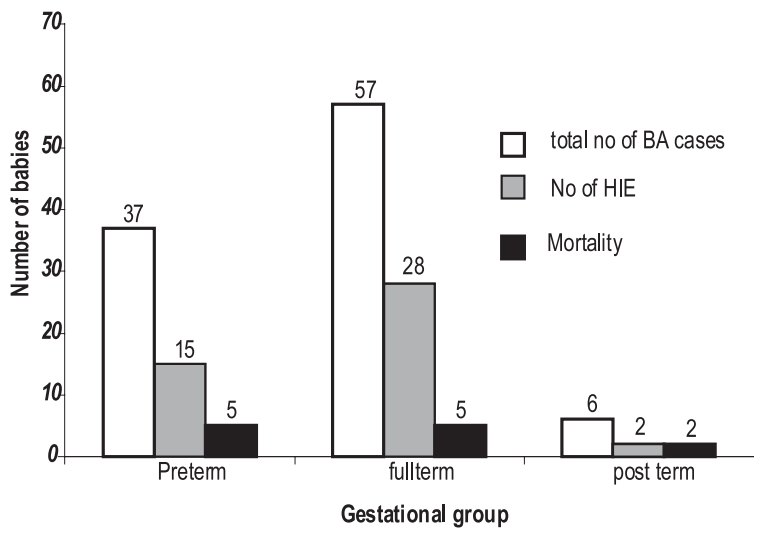

Fig-3: HIE Cases among different gestational age group of the asphyxiated babies with their mortality

\section{Discussion}

This study was on analysis of risk factors and shortterm outcome of birth asphyxiated babies admitted in SCBU of Dhaka Medical College Hospital. The number of studies done so far in Bangladesh in this regard was only a few as reported from Dhaka Shishu Hospital $(\mathrm{BICH})$ and Institute of Post-graduate Medicine and Research (now BSMMU) 6,7 . Definition of birth asphyxia was simplified for easy communication with illiterate people. Moreover, strict adherence to the ventilatory need or biochemical parameters for defining asphyxia was not possible, because of limited laboratory support in our centre.

In this study, male: female ratio was approximately $3: 2$, both in case and control. This nearly approaches other studies ${ }^{10-13}$. Sixty percent of asphyxiated babies and $73.3 \%$ of the control group babies were inborn. However, $22 \%$ and $30 \%$ mothers respectively, were in regular antenatal checkup. This reflect the low awareness for antenatal checkup in our society, irrespective of social class or educational background, which delays timely prediction of high risk pregnancies and leads to development of birth asphyxia as well as other perinatal problems. Etuk, in his study, also showed that birth asphyxia was more prevalent in the unbooked cases ${ }^{14}$. In this study, maternal age did not show any association with birth asphyxia. This finding was consistent with Bhuiyan ${ }^{9}$ and Crawford ${ }^{15}$. They had also found that maternal age as an isolated event cannot be considered as a risk factor for birth asphyxia. No association was also found among the various educational levels of the mothers of cases and control. Parity was found to be an important factor. $57 \%$ of the asphyxiated babies were born to primi 
mothers, whereas in the control group, only 33.3\% mothers were primi. Bhuiyan also found similar result in his study ${ }^{9}$. Prolonged labour, prematurity and low birth weight, which are common in primi, might be the possible explanation.

In this study, important maternal risk factors encountered more frequently among the asphyxiated babies were prolonged $2^{\text {nd }}$ stage of labour, PROM, toxaemia of pregnancy, hypertension, use of oxytocin during labour and APH. These findings are consistent with many other studies ${ }^{5,16}$. Malpresentation was found to be associated with increased risk in the study of Daga AS but it was not found in this study ${ }^{16}$. Incidence of caesarian section delivery in this study was 51\% among the asphyxiated group mothers and $63.3 \%$ in the control group mother. Timely intervention with caesarian section could have saved many of these unfortunate babies from being asphyxiated at birth.

Mean age of the babies, on admission was 13.8 hours in the asphyxiated group and 2.6 days in control group. Asphyxiated babies needed earlier admission for resuscitation or had other different serious complications.

In this study, $37 \%$ of the asphyxiated babies were preterm, $57 \%$ were term and $6 \%$ were post-term. Bhuiyan in her study in 1996 found 24\% preterm, $68 \%$ term and $8 \%$ post-term ${ }^{9}$. Ergander ${ }^{17}$ also found similar result in a study of 116 cases of severe birth asphyxia, (34.5\% preterm, and $65.5 \%$ term). In the present study, mean birth weight was $2407 \mathrm{gm}$ vs. control $2031.7 \mathrm{gm}$, which is similar to the findings of Goldberg ${ }^{18}$.

Death rate was found to be $16 \%$ in the asphyxiated babies vs. none in the control group. It is consistent with the study of Etuk ${ }^{14}$, who found it to be $20.8 \%$. Similar results were also observed in Indian and African studies. Mortality seen in the study of Khatoon ${ }^{5}$ in 1989 and Bhuiyan ${ }^{9}$ in 1996 was $25.4 \%$ and 44\% respectively. Whether this can be considered as a reflection of improvement in perinatal care in this country over the last decade, needs to be reconsidered.

The complications observed in the present study were HIE (45\%), convulsion (31\%), hyperbilirubinaemia (20\%), apnoea (16\%) and septicemia (16\%). It was observed in this study, that the mortality was enhanced by prematurity, low birth weight and severity of HIE. Most serious complication was the development of
HIE among post term babies which was seen to be uniformly fatal. Other studies also found similar results $^{10,19}$. Serious neonatal complications were infrequent among the control group.

This paper is prepared from the dissertation for the FCPS II Part, which was submitted and accepted on July 2005. Because of time limitation, number of control was limited 30 which should be, ideally, eaqual to study group. Moreover, they were taken from the SCBU, excluding the both asphyxiated babies and other groups which has clearly their own risk factors.

\section{Conclusion}

This study found birth asphyxia was more common in term babies than preterm babies. Most of the identified maternal risk factors were significantly related to asphyxia. Among the serious neonatal complications HIE was commonest in term asphyxiated neonates and mortality was higher in neonates with HIE. It could be possible to reduce the occurance of asphyxia and its complications by improving antenatal, intraparterm and neonatal care services within our limited resources.

\section{References}

1. McIntosh N. The Newborn. In: Mclntosh N, Helms PJ, Smyth LR editors. Forfar \& Arneil's Textbook of Pediatrics. 7th edition. Newyork: Churchill Livingstone; 2008. p. 177-392.

2. State of the World's Children, UNICEF; 2009.

3. Kolatal T, Vanprapar N, Thitadilok W. Perinatal asphyxia : multivariate analysis of risk Factors. J Med Assoc Thai 2000; 83: 1039-44.

4. State of World's Newborns, Bangladesh: Saving Newborn Lives Initiatives; Sept 2001.

5. Khatoon SA, Kawser CA, Talukder M Q-K. Clinical spectrum and outcome of birth asphyxiated babies in neonatal unit of IPGMR : A study of 122 cases. BJCH 1989; 13: 7-15.

6. Chowdhury MAKA, Banu K, Rahman M, Rahman M. Birth asphyxia- a prospective study in Dhaka Shishu Hospital. DS (Child) HJ 1996; 12: 18-22.

7. Annual Report of Dhaka Medical College, 2001.

8. Annual Report of Dhaka Medical College, 2007.

9. Bhuiyan SJ. Incidence, risk factors and immediate outcome of Asphyxia Neonatorum in 
hospitalized neonates: Dept. of Paed IPGMR [Dessertation]. Dhaka: BCPS; 1996.

10. Mulligan JC, Painter MJ, O' Donoghue PA. Neonatal Asphyxia: Neonatal mortality and long term sequelae. The Journal of Pediatrics 1980; 96: 903-07.

11. Hutchison JH. Practical Paediatric Problem. 6th ed. PG Publishing Pte Ltd; 1986.

12. Russel G, Dear J. Which deliveries require pediatricians in attendance? BMJ 1984; 289: 43536.

13. Drage JS, Kennedy C, Berendes H. Perinatal Asphyxia: Factors which predict developmental outcome. Scheiner AP Dev Med Child Neurol 1980; 22: 102-04.

14. Etuk SJ, Etuk IS. Relative risk of Birth asphyxia in babies of booked woman delivered in unorthodox health facilities in Calabar, Nigeria. Acta Trop 2001; 79: 143-47.

15. Crawford JS. Maternal age as an isolated factor in the incidence of Perinatal asphyxia. Am J Obst Gynecol 1996; 94: 281-82.

16. Daga AS, Daga ER, Patole SK. Risk Assessment of Birth Asphyxia. J Trop Pediatr 1990; 36: 3439.

17. Ergander U, Eriksson M, Zetterstrom R. Severe neonatal asphyxia: Incidence and prediction of outcome in Stockholm area. Acta Pediatr Scand 1983; 72: 321-25.

18. Goldberg RN, Caba LA, Sinatra ER, Plajstek CE, Hodgman JE. Hyperammonaemia associated with perinatal asphyxia. Pediatrics 1979; 64: 336-41.

19. Tabib SMSB. Clinical Profile of low birth weight babies - A study of 125 hospitalized neonates [Dissertation]. Dhaka: BCPS; 1987. 